\title{
The Role of Medication Beliefs on Medication
} Adherence in Middle Eastern Refugees and Migrants Diagnosed with Hypertension in Australia

This article was published in the following Dove Press journal:

Patient Preference and Adherence

\author{
Wejdan Shahin (D) \\ Gerard A Kennedy ${ }^{1-3}$ \\ Wendell Cockshaw' \\ leva Stupans (D) \\ 'School of Health and Biomedical \\ Sciences, RMIT University, Bundoora, \\ Victoria 3083, Australia; ${ }^{2}$ School of \\ Science, Psychology and Sport, \\ Federation University, Ballarat, \\ Melbourne, Australia; ${ }^{3}$ Institute for \\ Breathing and Sleep, Austin Health, \\ Melbourne, Australia
}

Purpose: The study assessed the association between medication beliefs and adherence in Middle Eastern refugees and migrants in Australia, and also examined differences between the two groups regarding beliefs and adherence to medication.

Patients and Methods: A total of 319 Middle Eastern refugees and migrants with hypertension were approached via various social groups in Australia and asked to complete Arabic versions of the Beliefs about Medicine Questionnaire (BMQ) and the Medication Adherence Questionnaire. BMQ scores (necessity and concerns scales) were classified as "accepting", "indifferent", "ambivalent" or "skeptical". Multiple mediation modelling was applied to examine the role of necessity and concerns scales as mediators between migration status and medication adherence.

Results: There were significant associations between medication adherence and medication beliefs scores (necessity and concerns scales) $(p=0.0001)$. Necessity and concern were mediators in the relationship between migration status and medication adherence. Significant differences were found between refugees and migrants for medication adherence and medication beliefs. Refugees were likely to have less necessity, and more concern beliefs than migrants, and were also less likely to adhere to medications. Almost $30 \%$ of refugees could be classified as skeptical and $40 \%$ as ambivalent. In contrast, $50 \%$ of migrants had accepting beliefs, and around $35 \%$ held ambivalent beliefs. Refugees and migrants with "accepting" beliefs reported the highest adherence to medication and those holding "skeptical" beliefs reported the lowest adherence.

Conclusion: Medication beliefs are potentially modifiable and are reasonable targets for clinical interventions designed to improve medication adherence. Understanding these beliefs and the likely differences between refugees and migrants is crucial to provide specific and targeted advice to each group independently in order to improve medication adherence and overall health.

Keywords: medication beliefs, concerns, necessity, medication adherence, migrants, refugees, Middle Eastern

\section{Introduction}

Essential hypertension is an epidemic affecting approximately a quarter of all adults worldwide $^{1}$ with high mortality and morbidity when not treated or adequately controlled, especially in vulnerable populations. ${ }^{2}$ In $2015,5.8 \%$ of the total loss of healthy life in Australia was due to high blood pressure. ${ }^{3}$ The effective control of hypertension requires patients to adopt and maintain a healthy lifestyle and take
Correspondence: Wejdan Shahin RMIT University, PO Box 7I, Bundoora, Victoria 3083, Australia

Email wejdan.shahin@rmit.edu.au 
medication regularly. ${ }^{4}$ However, medication nonadherence constitutes a significant obstacle to hypertension care worldwide with a prevalence between $20 \%$ and $50 \%{ }^{5}$ In Australia, the mean non-adherence to antihypertensive therapy is about $15 \%{ }^{6}$ Poor adherence is considered a major problem and is associated with suboptimal clinical outcomes, increased emergency-room visits, and hospitalizations all of which contribute to an increased burden on the health-care system. ${ }^{7}$

Effective strategies for the treatment of hypertension should include a good understanding of the barriers to medication adherence. Different factors may influence patient adherence to hypertension medications ranging from patient-related characteristics such as gender, and age, to the duration of having hypertension, and the frequency of blood pressure measurement." ${ }^{8,9}$ In addition, there are other several factors of which patients' beliefs about medication are considered an important aspect in their motivation to take the medication as prescribe. ${ }^{10}$ Medication beliefs are thought to be more consistent in predicting adherence than demographic variables, and account for almost $20 \%$ of the variance in adherence behaviour. ${ }^{11}$ In addition, medication beliefs are considered by some health sociologists as hidden determinants of any treatment outcome and considered a critical predictor of medication adherence. $^{12}$

Two dimensions of medication beliefs have shown promise for identifying potential targets for interventions to improve medication adherence according to the oftenused Necessity-Concern Framework. ${ }^{13,14}$ This suggests that patients weigh up their perceived personal need for treatment against their concerns about potential adverse effects of treatment when deciding whether or not to adhere to medications. ${ }^{13}$ Thus, medication adherence will be greater when the difference between patients' beliefs in the necessity of the medication exceed their concerns. ${ }^{14}$ The Beliefs about Medicines Questionnaire (BMQspecific) has two subscales to assess patients' perceived need for treatment (necessity) and their concerns about potential adverse effects (concerns). ${ }^{13,15}$ A relatively recent meta-analysis ${ }^{16}$ has described how beliefs about medicines determined through the BMQ are correlated to medication adherence in a number of chronic illnesses, including hypertension, and reported that medication adherence was correlated positively with necessity beliefs, and negatively with concern, across the majority of included studies.
The management of hypertension adds a new demand to already existing daily life tasks, especially in vulnerable populations, ${ }^{17}$ such as refugees under stress after fleeing from their home countries to seek safety. Over the past years, conflicts in some of Middle Eastern countries, such as Lebanon, Algeria, Sudan, Libya, Iraq, and Syria have contributed to the many hundreds of thousands of refugees seeking safety in neighbouring states and in more distant countries, such as Australia which has ranked as one of the top three resettlement countries in the world. ${ }^{18}$ According to the Refugee Council in Australia, more than 900,000 refugees have been accepted in Australia since 1947, with the current top countries of origin for refugees being Iraq and Syria. ${ }^{19}$

Refugees defined according to the 1951 Refugee Convention as a person who relocates from their

Country of nationality or habitual residence, has a wellfounded fear of persecution because of his (sic) race, religion, nationality, membership of a particular social group or political opinion, and is unable or unwilling to avail themselves of the protection of that country, or to return there, for fear of persecution. ${ }^{20}$

Often the terms "migrant", and "refugee" are used interchangeably, and both migrants and refugees have been considered as a single population, and considered under the same umbrella. ${ }^{21}$ However, each has an explicit legal definition that distinguishes one from the other. ${ }^{22}$ Refugees forced to leave their countries of origin because of a direct threat of persecution or death, and cannot safely return home, whereas migrants face no such impediment to returning to their country of origin as they choose to move mainly to improve their lives by finding work, or in some cases for education, family reunion, or other reasons. ${ }^{23}$

It has been reported in the literature that migrants and refugees have an elevated prevalence of medical diseases, such as hypertension. Although both these populations may have similar difficulties during the resettlement processes, several factors distinctly differentiate the social and personal lives of refugees and migrants. These factors may include the intentions and motivations for migration, the impediments to returning back to home countries, having a control over their lives through migration, and taking into account the damaging effect of persecution on their education, employment, and socioeconomic status. ${ }^{24}$ Therefore, these two different populations might evolve different beliefs about their medications. A previous cross-sectional study was 
carried out by the authors to understand the differences between Middle-Eastern refugees and migrants regarding their illness perceptions and found that refugees have poor understanding of the causes and symptoms of hypertension, and are less likely to control their illness than their migrants counterpart. ${ }^{24}$ This may potentially influence their perception of the necessity to take their prescribed medications or the concern about the sideeffects of taking these medications. Thus, it is important to have a well-founded understanding of how Middle Eastern refugees and migrants perceive their prescribed medicine, and how these beliefs about medicines may impact medication adherence.

Medication non-adherence in the Middle Eastern population was addressed in a systematic review and estimated to be $48 \%$ in chronic illnesses, such as hypertension, diabetes and chronic obstructive pulmonary disease. ${ }^{25}$

According to a recent systematic review that evaluated the impact of several health beliefs on medication adherence ${ }^{26 \text {, }}$ patients' beliefs and their relationship to medication adherence appear to vary unpredictably across and within populations. ${ }^{26}$ This suggests the importance of understanding the differences between different populations such as refugees and migrants regarding medication beliefs and adherence. In addition, only a single study was found in this systematic review that was conducted in a Middle Eastern country. The study found that higher medication adherence was significantly related to fewer perceived concern beliefs. ${ }^{27}$ However, this study was not an evaluation of refugees' or differences between Middle Eastern refugees and migrants.

To date, there has not been any research that has investigated the role of medication beliefs on medication adherence of Middle Eastern hypertensive refugees and migrants in Australia or indeed in other countries, or that has assessed the differences between these two groups regarding their beliefs about medications. The aim of this study was to explore the relationship between beliefs about medicine and adherence in Middle Eastern refugees and migrants in Australia, and to assess the differences between both groups with regards to medication beliefs and adherence.

\section{Patients and Methods Study Design and Setting}

After obtaining ethics approval from RMIT University Ethics Committee (SEHAPP 53-18), this study was conducted as a part of a larger cross-sectional study in several avenues that were selected because they specialise in supporting Middle Eastern refugees and migrants including, two Facebook groups that have more than 6000 Middle-Eastern refugees and migrants across different states in Australia, and in several social groups organised by Victorian Arabic Social Services across Victoria (VASS). In addition, refugees and migrants were recruited from Kangan Institute, Melbourne through its Adult Migrant English Program, where migrants and refugees learn English. The survey was generated using Qualtrics to enable online data collection. A post in Arabic about the survey and the link to it was placed on the home pages of Arabic Face-book groups, inviting members to participate in the survey. Online survey data were collected automatically via the Qualtrics system. A paper-based survey was also provided for those who were unable to access the survey online. We were invited by VASS to be part of their social group sessions across Victoria to give refugees and migrants information about health issues. After the sessions, interested participants who consented to taking part in the study were given paper copies of the survey.

\section{Study Participants}

Study participants have been reported and published previously. ${ }^{24}$ Participants who attended the abovementioned social groups and English language centre were approached and invited to consider participating in the study throughout 10-month recruitment period. Inclusion criteria were: 1) aged 30 years or older; 2) diagnosed with hypertension; and 3) had migrated to Australia from one of the 22 countries in the Middle East, as refugees or migrants. One of the survey questions was to identify the status of migration of participants (refugee or migrant). In this question, we asked participants to describe how they arrived at Australia. The choices were "refugee," "work," "studying," "economic reasons" "any other reason". Migrants were defined as those participants who selected any choices of other than "refugee".

\section{Development of Questionnaire}

The self-administered questionnaire consisted of 21 items divided into four sections. The first section comprised socio-demographic information including age, gender, place of birth, migration status, education level, and occupation. In the second section, participants were asked to identify whether they had one or more than one of eight significant chronic conditions as categorised by the Australian Institute of Health and Welfare. These 
conditions include arthritis, asthma, back pain and associated problems, cancer, cardiovascular disease (such as hypertension, coronary heart disease and stroke), chronic obstructive pulmonary disease (COPD), diabetes and mental health conditions. ${ }^{28}$

To measure medication adherence we used the validated and reliable four-item Medication Adherence Questionnaire (MAQ) ${ }^{29}$ This questionnaire assesses both intentional and unintentional non-adherence. The scale is scored 1 point for each "no" and 0 points for each "yes". Patients were described as adherent (if the total score was four) or non-adherent (if the total score was less than 4). ${ }^{30}$ This questionnaire was selected because it has been used across many chronic illnesses, such as cardiovascular disease, and has demonstrated adequate predictive validity and good reliability. ${ }^{31}$ The psychometric properties have been reported to range from adequate ${ }^{29,32}$ to high. ${ }^{33}$

Beliefs regarding medications were measured using Beliefs about Medicine Questionnaire (BMQ). ${ }^{34}$ The BMQ-specific is a 10 -item questionnaire that comprised of two scales; a 5-item necessity scale that assesses perceived personal need for the medication (necessity), and a 5 -item concerns scale that assesses common concerns about potential adverse effects such as dependence, adverse effects, or accumulation effects (concerns). Participants indicate how much they agree with a series of statements on a 5-point scale from strongly agree to strongly disagree. Subscales scores were calculated as mean item scores. Higher scores indicate a stronger endorsement of the construct being measured. ${ }^{13}$ Following the necessity concerns framework, the difference between necessity and concern subscale scores was calculated in order to evaluate the patient-perceived, cost-benefit, analysis of medication adherence. ${ }^{15}$

The questionnaires were piloted by collecting data from 100 participants and completing preliminary analyses to determine the need for modification of any questions. No modifications were required. The questionnaires were available in English language and were translated to Arabic language by a bilingual researcher whose first language was Arabic, and then they were back-translated to English by another bilingual researcher. The original questionnaires were compared with the back-translated version by two researchers whose first language was English. No significant differences or changes in meaning were detected and hence the translated questionnaires were used in the study. The questionnaires were offered in both languages depending on the participants' preferences.

\section{Sample Size}

Initial power calculations were done using G-Power* software and in doing this we allowed for missing data. The sample size was calculated based on $95 \%$ confidence intervals, power of $80 \%$, and medium effect size (0.3). To estimate effect size, means and SD derived from the study of the outcome variable (medication adherence) were used. Sample size of 222 participants (111 in each group; refugees, migrants) was calculated.

\section{Data Analysis}

The MAQ employs dichotomous items; therefore, KuderRichardson's coefficient (KR20) was used to assess the reliability $^{35}(\alpha=0.76)$, while the BMQ scale reliability was assessed using Cronbach's $\alpha$. Reliability coefficients were 0.94 and 0.90 for necessity and concerns, respectively. The Cronbach's $\alpha$ for both scales of the original English version of the BMQ was $0.76 .^{34}$ IBM Statistical Package for the Social Sciences software (Ver. 26) for Windows was used to analyse all the data.

All dependent variables and participants' sociodemographics characteristics were analysed using descriptive statistics including means and standard deviations and percentages and frequencies. Socio-demographics characteristics for this sample have been published previously, ${ }^{24}$ and are reproduced here in Table 1. Pearson's correlations $(r)$ were used to examine the bivariate associations for dependent variables. Chi-square tests were used to examine the associations of independent and dependent variables for the two groups, while independent $t$-tests was used to examine the differences between the two groups. A two-tailed significance level of $p<0.05$ was used to evaluate all statistical analyses.

A multiple mediation model in which necessity and concern mediate the association between migration status (refugee or migrant) and medication adherence was tested as presented in Figure 1. In order to analyse the model and determine the confidence interval for the indirect effect, bootstrapping (5000 samples) was applied using the SPSS PROCESS macro. ${ }^{36}$ We chose this process because it does not require the distribution of the indirect effect to be normal. ${ }^{37,38}$ If the $95 \%$ bias-corrected confidence interval does not include zero, the indirect effect is statistically significant. Confounding factors that were significantly associated with medication adherence were entered in the mediation analysis as covariates.

Based on the empirical and theoretical framework, ${ }^{39}$ cluster analysis was conducted to examine the differences 
Table I Demographics and Clinical Characteristics for Refugees and Migrants $(N=319)^{24}$

\begin{tabular}{|c|c|c|c|c|c|c|}
\hline \multicolumn{2}{|l|}{ Variables } & \multirow{2}{*}{$\begin{array}{l}\text { Refugee } n= \\
168 \\
n(\%)\end{array}$} & \multirow{2}{*}{$\begin{array}{l}\text { Migrant } n= \\
\text { I5 I } \\
n(\%)\end{array}$} & \multirow[t]{2}{*}{$\chi^{2}(d f)$} & & \multirow{2}{*}{$\begin{array}{l}\text { Total Participants } \\
n=319 \\
\text { n (\%) }\end{array}$} \\
\hline & & & & & & \\
\hline \multirow[t]{4}{*}{ Age } & $30-40$ & $23(13.8 \%)$ & 29 (19.2\%) & $20.78(3)$ & 0.001 & $52(16.3 \%)$ \\
\hline & $4 I-50$ & 35 (21\%) & 59 (39.1\%) & & & 94 (29.4\%) \\
\hline & Above 50 & $108(64.7 \%)$ & $60(39.7 \%)$ & & & I 68 (52.5\%) \\
\hline & Missing & $2(1.2 \%)$ & 3 (I.98\%) & & & 5 (I.5\%) \\
\hline \multirow[t]{2}{*}{ Sex } & Male & $83(49.4 \%)$ & $64(42.4 \%)$ & $1.58(I)$ & 0.20172 & 147 (45.9\%) \\
\hline & Female & $85(50.6 \%)$ & 87 (57.6\%) & & & 172 (53.7\%) \\
\hline \multirow[t]{6}{*}{ Education } & Lower secondary & $88(53.7 \%)$ & $42(28.4 \%)$ & $40.57(4)$ & 0.0001 & $130(40.8 \%)$ \\
\hline & Higher secondary & $4 \mid(25 \%)$ & $26(17.6 \%)$ & & & $67(21 \%)$ \\
\hline & Diploma & 7 (4.3\%) & $18(12.2 \%)$ & & & $25(7.8 \%)$ \\
\hline & Bachelor & $22(13.4 \%)$ & 34 (23\%) & & & $56(17.6 \%)$ \\
\hline & Higher than bachelor & $6(3.7 \%)$ & $28(18.9 \%)$ & & & $34(10.7 \%)$ \\
\hline & Missing & $4(2.3 \%)$ & $3(1.98 \%)$ & & & 7 (2.2\%) \\
\hline \multirow[t]{4}{*}{ Occupation } & Home/Not working & 139 (84.8\%) & $84(55.6 \%)$ & $38.35(2)$ & 0.001 & $223(69.9 \%)$ \\
\hline & Self-employer & $4(2.4 \%)$ & $3 \mathrm{I}(20.5 \%)$ & & & $34(10.7 \%)$ \\
\hline & Governmental/private & $2 \mathrm{I}(12.8 \%)$ & $36(23.8 \%)$ & & & 57 (I7.9\%) \\
\hline & Missing & $4(2.3 \%)$ & - & & & $4(2.3 \%)$ \\
\hline \multirow{5}{*}{$\begin{array}{l}\text { Arrival year to } \\
\text { Australia }\end{array}$} & $2015-2018$ & $58(34.7 \%)$ & $23(15.4 \%)$ & $24.35(3)$ & 0.0001 & $8 \mathrm{I}(25.4 \%)$ \\
\hline & $2010-2015$ & $55(32.9 \%)$ & $42(28.2 \%)$ & & & 97 (30.4\%) \\
\hline & $2000-2010$ & $33(19.8 \%)$ & $4 \mathrm{I}(27.5 \%)$ & & & 74 (23.2\%) \\
\hline & Before 2000 & 21 (I2.6\%) & 43 (28.9\%) & & & $64(20 \%)$ \\
\hline & Missing & I (0.6\%) & $2(1.3 \%)$ & & & $3(0.9 \%)$ \\
\hline \multirow[t]{7}{*}{ Comorbidities } & Having $\geq 2$ chronic illnesses & $54(32.1 \%)$ & $35(23.2 \%)$ & $5.5(I)$ & 0.02 & $87(27.3 \%)$ \\
\hline & Diabetes Mellitus & 61 (39.4\%) & $38(25.7 \%)$ & $6.44(\mathrm{I})$ & 0.01 & 99 (31.1\%) \\
\hline & Mental illness & $12(7.4 \%)$ & $3(2 \%)$ & $4.98(I)$ & 0.03 & 15 (4.7\%) \\
\hline & COPD & 7 (4.2\%) & $6(4 \%)$ & $0.01(\mathrm{I})$ & 0.9 & $13(4 \%)$ \\
\hline & Asthma & $16(10.3 \%)$ & 14 (9.5\%) & $0.06(I)$ & 0.8 & 30 (9.4\%) \\
\hline & Back pain & 57 (35.4\%) & $42(28 \%)$ & $1.96(1)$ & 0.16 & 99 (31.1\%) \\
\hline & Arthritis & $42(26.3 \%)$ & $36(24.2 \%)$ & $0.18(\mathrm{I})$ & 0.67 & 78 (24.5\%) \\
\hline \multirow[t]{11}{*}{ Country of birth } & Iraq & $83(49.4 \%)$ & 17 (II.2\%) & - & - & $100(31.4 \%)$ \\
\hline & Syria & $54(32.1 \%)$ & $18(11.8 \%)$ & - & - & $72(22.6 \%)$ \\
\hline & Lebanon & $17(10.12 \%)$ & 45 (29.6\%) & - & - & 62 (19.4\%) \\
\hline & Egypt & $3(1.8 \%)$ & $18(11.8 \%)$ & - & - & $21(6.6 \%)$ \\
\hline & Morocco & $2(1.2 \%)$ & II (7.23\%) & - & - & $13(8.6 \%)$ \\
\hline & Jordan & NA & $13(8.55 \%)$ & - & - & $13(8.6 \%)$ \\
\hline & Algeria & I (0.6\%) & $5(3.3 \%)$ & - & - & $6(1.9 \%)$ \\
\hline & Kuwait & NA & $9(6.3 \%)$ & - & - & $9(6.3 \%)$ \\
\hline & Emirates & NA & $4(2.8 \%)$ & - & - & $4(2.8 \%)$ \\
\hline & Saudi Arabia & NA & $4(2.8 \%)$ & - & - & $4(2.8 \%)$ \\
\hline & Other Arab countries & $6(3.6 \%)$ & 8 (5.3\%) & - & - & 14 (4.4\%) \\
\hline
\end{tabular}

between refugees and migrants medication beliefs, and to examine the association of these clusters with medication adherence. Firstly, four groups were generated by splitting the scores from necessity and concerns items at the median; subsequently, participants were categorized, according to Horne et al, ${ }^{40}$ into one of four subgroups according to their attitudes towards medication; Skeptical (low necessity, high concerns), Ambivalent (high necessity, high concerns), Indifferent (low necessity, low concerns), and Accepting (high necessity, low concerns). Following this, 


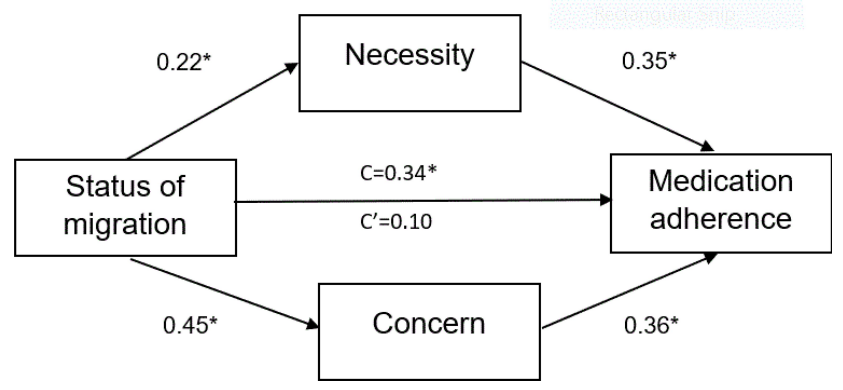

Figure I Medication beliefs as a mediator between status of migration and adherence to medications. *Indicates significant value $-p<0.05$.

associations between adherence rates and the four belief groups were examined in both groups, and differentiated using Chi-square tests, and analysis of variance.

\section{Results}

\section{Participants' Demographics and Clinical Characteristics}

A total of 319 participants were recruited: 168 refugees, and 151 migrants. A total of 108 participants were recruited throughout the Facebook groups, while the rest of participants were recruited from the other of organisations. From these organisations questionnaires were returned by 211 of 300 participants (response rate $70.3 \%$ ). Although the questionnaires were available in both languages; Arabic and English, only twenty-one surveys were answered in English by refugees and migrants, while the rest of surveys were answered in Arabic language.

All participants were originally born in the Middle East with the highest proportion of refugees were from Iraq and Syria. Significant differences between refugees and migrants regarding demographics and clinical characteristics were found (Table 1). This has been discussed elsewhere. ${ }^{24}$ There were slightly more women than men in both groups. Broadly, differences reflect the characteristics expected in these groups. Refugees had lower levels of education $\left(\chi^{2}=40.57, p=0.0001\right)$, reported more comorbid conditions $\left(\chi^{2}=5.5, p=0.02\right)$, were more likely unemployed $\left(\chi^{2}=38.35, p=0.0001\right)$, and were significantly older than migrants $\left(\chi^{2}=20.78, p=0.001\right)$.

\section{Participants' Beliefs About Medications and Medication Adherence}

Significant differences were found between refugees and migrants with regards to medication adherence and beliefs about medicines (Table 2). Refugees had substantially lower adherence than migrants with a large effect size ( $p=0.0001, d=0.81)$, and they reported a significantly lower level of necessity beliefs with a medium effect size ( $p=0.0001, d=0.48$ ). Refugees also demonstrated significantly higher concern beliefs about medicines than migrants with a large to very large effect size $(p=0.0001$, $d=1.04)$. Importantly, the association between necessity and concern beliefs was low $(r=-0.20, p=0.02)$, indicating that concern beliefs are not strongly contingent upon necessity beliefs. This confirms that necessity and concerns beliefs lie on different continua.

\section{Association Between Demographics Characteristics, Medication Beliefs and Medication Adherence}

Participants who reported higher levels of education were more likely to adhere to medications (refugees: $r=0.24$, $p=0.003$; migrants: $r=0.29, p=0.001$ ).

Medication beliefs were correlated with adherence in both groups (Table 3 ). Necessity beliefs for taking medications were positively associated with medication adherence in refugees $(r=0.4, p=0.0001)$ and migrants $(r=0.35$, $p=0.0001)$. In contrast, participants who reported higher level of concerns beliefs related to adverse effects, and addiction regarding prescribed medicines showed negative association with medication adherence in refugees $(r=$ $-0.34, p=0.0001)$ and migrants $(r=-0.5, p=0.0001)$. Medication adherence was significantly correlated with beliefs in the necessity of the medication when it exceeded concerns (refugees $r=0.55, p=0.0001$ and migrants $r=0.6$, $p=0.0001)$.

Table 2 Comparisons of Refugee and Migrant Medication Beliefs, and Medication Adherence

\begin{tabular}{|l|l|l|l|l|l|}
\hline & Refugee M(SD) & Migrant M(SD) & Cohen's d & $\boldsymbol{t}(\mathbf{d f})$ & $\boldsymbol{P}$ \\
\hline Necessity beliefs & $17.8(5.5)$ & $20.2(4.4)$ & 0.48 & $4.2(308)$ & $0.000 \mathrm{I}$ \\
Concern beliefs & $18.9(4.4)$ & $13.7(5.5)$ & 1.04 & $8.7(277)$ & $0.000 \mathrm{I}$ \\
Medication adherence & $1.36(1.4)$ & $2.5(1.4)$ & $0.8 \mathrm{I}$ & $7.26(305)$ & 0.0001 \\
\hline
\end{tabular}


Table 3 Correlations Between Medication Adherence Scores and Other Variables in Refugees and Migrants

\begin{tabular}{|c|c|c|c|c|c|c|c|c|c|c|}
\hline & I & 2 & 3 & 4 & 5 & 6 & 7 & 8 & 9 & 10 \\
\hline I. Adherence & 1.00 & $0.40 *$ & $-0.34^{*}$ & $0.52^{*}$ & 0.06 & 0.10 & 0.14 & $0.24 *$ & -0.09 & -0.11 \\
\hline 2. Necessity & $0.35^{*}$ & 1.00 & $-0.26^{*}$ & $0.84 *$ & -0.08 & -0.04 & -0.14 & 0.18 & -0.11 & -0.09 \\
\hline 3. Concern & $-0.50^{*}$ & -0.21 & 1.00 & $-0.75^{*}$ & -0.06 & -0.08 & 0.15 & -0.16 & -0.05 & $0.24 *$ \\
\hline 4.Necessity-Concern & $0.58^{*}$ & $0.700 *$ & $-0.85^{*}$ & 1.00 & 0.001 & 0.02 & -0.15 & 0.23 & -0.05 & $-0.23 *$ \\
\hline 5.Age & -0.00 & -0.15 & 0.12 & -0.15 & 1.00 & 0.07 & 0.06 & -0.21 & 0.08 & 0.17 \\
\hline 6. Gender & -0.02 & 0.11 & -0.00 & 0.04 & -0.02 & 1.00 & -0.49 & -0.14 & $0.25^{*}$ & 0.16 \\
\hline 7. Employment & 0.13 & 0.11 & -0.35 & 0.33 & -0.03 & $-0.50^{*}$ & 1.00 & -0.08 & -0.12 & -0.21 \\
\hline 8. Education & $0.26^{*}$ & -0.00 & -0.14 & 0.10 & $-0.35^{*}$ & -0.09 & 0.22 & 1.00 & -0.17 & -0.17 \\
\hline 9. Arrival year & -0.11 & -0.11 & 0.22 & -0.20 & $0.46 *$ & 0.15 & -0.21 & $-0.34 *$ & 1.00 & -0.10 \\
\hline 10. Comorbidity & 0.04 & 0.27 & -0.01 & 0.15 & $0.27^{*}$ & 0.07 & 0.002 & -0.18 & 0.18 & 1.00 \\
\hline
\end{tabular}

Notes: Correlations for refugees above the diagonal; Correlations for migrants below the diagonal; *Indicates $\mathrm{p}<0.05$; employment coded dichotomously.

\section{Necessity and Concern as Mediators Between Migration Status and Illness Perceptions}

After adjusting for employment, comorbidity and educational level, the relationship between migration status (refugee or migrant) and medication adherence was mediated by both concern about and necessity of taking medication. The standardized regression coefficient between migration status was statistically significant with necessity $(p=0.004)$, and concern $(p=0.0001)$. Also, the standardized regression was statistically significant between status of migration and medication adherence ( $p=0.0001$ ). We tested the significance of this indirect effect using bootstrapping procedures. The standardized indirect effect for necessity was 0.08 , and the $95 \%$ confidence interval ranged from 0.03 to 0.12 , and for concern 0.16 and the $95 \%$ confidence interval ranged from 0.10 to 0.23 . Thus, the indirect effect was statistically significant (see Table 4 and Figure 1).

\section{Cluster Analysis}

$\mathrm{K}$ mean cluster analysis showed that medication beliefs were distributed into four subtypes shown in Figure 2. Migrants were significantly more likely to hold accepting beliefs than refugees, who were likely significantly more likely to hold skeptical or ambivalent beliefs $\left(\chi^{2}=67.3, p=0.0001\right)$. Analysis of variance showed medication adherence was significantly higher in refugees holding Accepting beliefs than in those holding Ambivalent $(p=0.0001,95 \%$ CI $0.5-$ 2.4 ), or Skeptical beliefs $(p=0.04,95 \%$ CI $0.01-1.98)$. Migrants who reported accepting beliefs were significantly more likely to adhere to prescribed medications than those holding skeptical ( $p=0.0001,95 \%$ CI $0.6-2.37$ ), ambivalent $(p=0.0001,95 \%$ CI $0.7-1.89)$, and/or indifferent beliefs $(p=0.001,95 \%$ CI 0.56-2.7).

\section{Discussion}

This is the first study to explain the relationship between medication adherence and medication beliefs in Australia using multiple mediation modelling, and to differentiate between Middle Eastern refugees and migrants regarding their beliefs about medicine and medication adherence.

This study identified significant differences between Middle Eastern refugees and migrants. Migrants diagnosed with hypertension, have more positive beliefs about their medications than refugees, believing that medications are necessary for their chronic illness, and hold less concerns about the adverse effects and the possible dependency on medications. Also, migrants reported significantly higher medication adherence levels than refugees from Middle East.

The clusters formed in this analysis and the results are consistent with the categories formed by Horne et al in their analysis of the necessity-concerns framework. ${ }^{40}$ The evaluation of these clusters and their association with

Table 4 Bootstrap Analyses of the Magnitude and Statistical Significance of Indirect Effect

\begin{tabular}{|l|l|l|l|l|}
\hline $\begin{array}{l}\text { Independent } \\
\text { Variable }\end{array}$ & $\begin{array}{l}\text { Dependent } \\
\text { Variable }\end{array}$ & $\begin{array}{l}\text { Mediator } \\
\text { Variable }\end{array}$ & $\begin{array}{l}\text { Standardized Indirect } \\
\text { Effect }\end{array}$ & $\begin{array}{l}\text { 95\% CI Mean Indirect Effect (Lower and } \\
\text { Upper) }\end{array}$ \\
\hline $\begin{array}{l}\text { Status of migration } \\
\text { Status of migration }\end{array}$ & $\begin{array}{l}\text { Adherence } \\
\text { Adherence }\end{array}$ & $\begin{array}{l}\text { Necessity } \\
\text { Concern }\end{array}$ & 0.08 & $0.03-0.12$ \\
0.16 & $0.10-0.23$ \\
\hline
\end{tabular}




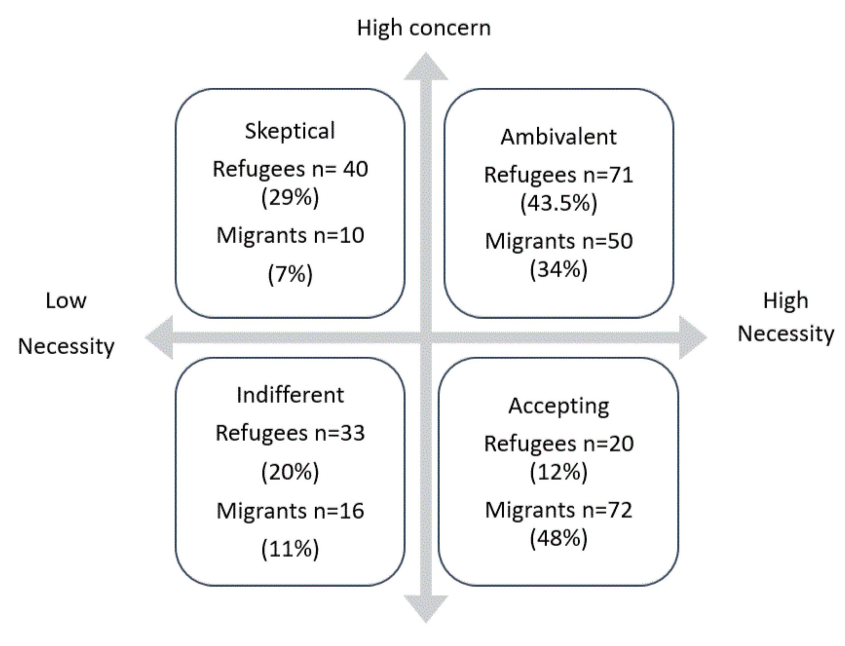

Low Concern

Figure 2 Distribution of migrants and refugees across each of the four medication beliefs groups.

medication adherence in both refugees and migrants is fundamental to developing specific and targeted interventions for both these groups.

Following from the findings of our study, interventions to improve medication adherence need to focus on the "skeptical" and "ambivalent" clusters. The two clusters constitute of more than $70 \%$ of refugees, and $40 \%$ of migrants who have high concern beliefs about medicines.

The patients in the skeptical cluster were found to have the lowest level of medication adherence, making the patients in this cluster a target for interventions that enhance medication adherence. Concern beliefs about medicine need to be reduced in both refugee and migrant groups and necessity beliefs need to be increased in refugees.

Though both skeptical and ambivalent patients are nonadherent, the type of interventions needed for each group is different. Understanding the characteristics of each these clusters for both refugees and migrants by healthcare providers may lead to appropriate interventions for improving medication-taking behaviours. ${ }^{41}$

The findings of the current study are also consistent to studies cited in the literature that have reported that having high accepting beliefs, and low skeptical beliefs are associated with higher medication adherence. ${ }^{13,31}$

Studies from Middle East are limited regarding medication beliefs and medication adherence. Our findings are consistent with those from a study conducted in Kuwait, ${ }^{7}$ that reported low adherence was associated with high concerns beliefs.
Medication beliefs may be modified with healthcare interventions and advice. These beliefs also are potentially influenced by various personal characteristics that may derive from culture and religion. ${ }^{12}$ Patients' cultural beliefs about medication-taking are also factors contributing intentional medication non-adherence. ${ }^{42}$ Healthcare providers should be encouraged to recognize confusion and misconceptions about medications in patients from different cultures and to provide sensitive care to people from diverse ethnic backgrounds to achieve better medication adherence. ${ }^{43}$

Taking prescribed medications regularly is imperative to maintaining adequate blood pressure control in most hypertensive patients, especially for refugees who have high levels of mortality due to chronic illnesses. ${ }^{44}$ Minimal medication adherence levels were reported by refugees in this study underscoring the importance of taking action to improve overall health of this vulnerable group of people in Australia.

Most refugees in this study came from countries that are currently involved in war or conflict. These countries experience severe disruptions of their health systems resulting in a high degree of uncertainty regarding the safety of seeking healthcare services. ${ }^{24}$ Moreover, patients are often reluctant to share intentions to not take medications and concerns with healthcare providers, and therefore providers need to create an encouraging, blame-free environment to allow patients to describe their medicationtaking behaviour. ${ }^{42}$

Social support plays a significant role in determining treatment uptake, adherence and improvement in health. Refugees with little or no social support show poorer medication adherence and recovery. ${ }^{21}$ Previously reported data $^{24}$ are consistent with literature which shows that Middle Eastern refugees have low educational levels low socioeconomic status ${ }^{45-48}$ and these factors negatively affect the quality of healthcare they obtain. In addition to income and education health literacy, employment status, insurance status and access to care also negatively affect health outcomes. ${ }^{49}$ However, longer duration of residency in the host countries has been associated with greater levels of medication adherence. ${ }^{51}$

Language is one major barrier for refugees in general practice. Refugees have a specific complexity to their health and social care needs. However, because of their limited English language, they are less likely to engender empathic response from doctors, establish rapport in these relationships, receive sufficient information about their 
health or participate in decision-making. Moreover, they are unable to communicate full details of their medical and social history. ${ }^{50}$ Therefore, they might be directed to gain information from their relatives, or friends who are diagnosed with the same illnesses, or maybe from Arabic websites that list all the potential indications and adverse effects of medications. This may exacerbate refugees' concerns about taking medications, making it difficult to understand the likely risks and possible benefits. During medical appointments, Arabic-speaking refugees might benefit from receiving consumer medicine information sheets in Arabic, designed specifically for those with lowlanguage literacy levels. Information sheets should include the common adverse effects and emphasize the benefits of taking medication to augment the medical counselling sessions.

There is evidence that indicates educational interventions change migrants' and refugees' concerns about medications and that this increases knowledge about hypertension and its treatment. ${ }^{41}$ This study highlights also, the importance of understanding the differences between refugees and migrants, and how each group has different beliefs about their medications. Acquiring an awareness of each population's beliefs about medicine may help healthcare providers to identify gaps in their own understanding and the expectations of refugees and migrants about treatments. This may lead to the provision of more optimal health care that meets the needs and expectations of each population. ${ }^{24}$

This study has some limitations, due to the crosssectional design, and self-report measures used to assess both medication adherence and medication beliefs. Selfreporting adherence might not be accurate due patients' poor memory and overestimation of adherence. Although using Facebook may have limited the number of older people in one-third of the sample, the other two-thirds of the sample recruited from community groups contained a good representation of older individuals. In addition, more than $50 \%$ of participants in this study were more than 50 years old, indicating that the method of recruitment was not a significant limiting factor. Facebook groups allowed us to access Arabic participants from all over Australia and this account for $30 \%$ of the sample, contributing to the generalizability of our findings. A minor limitation was collecting data from limited number of groups across Victoria, $70 \%$ of the sample.

The assessment of the validity of the Arabic versions of the questionnaires was beyond the scope of the current study. However, the English versions have been validated $^{34}$ and the translation process used in this study showed there was no loss of meaning and the internal consistency of the Arabic version was very high (see results section).

\section{Conclusion}

Medication beliefs have a significant impact on medication adherence. Healthcare providers need to understand the differences between refugees and migrants regarding their necessity and concern beliefs about medicines, and adherence prior to providing counselling, and medical advice. This study highlights the need for tailored interventions for each cluster of beliefs, and to understand the characteristics of these clusters, to provide optimal healthcare advice and counselling. This study recommended addressing non-adherence amongst vulnerable patients in future studies by reducing concerns and increasing necessity beliefs.

\section{Data Sharing Statement}

The datasets used and/or analysed during the current study are available from the corresponding author on reasonable request.

\section{Ethics Approval and Consent to Participate}

Ethics approval for this study was obtained from RMIT University Ethics Committee (SEHAPP 53-18). All participants provided informed consent, and this study was conducted in accordance with the Declaration of Helsinki.

\section{Acknowledgments}

The authors would like to thank Victorian Arabic Social Services, Kangan institute, Iraqi women's social groups, and the administrators of the included Facebook groups, for assisting in recruitment of participants.

\section{Author Contributions}

WS collected the sample, organised the data, analysed and interpreted the data using SPSS, and wrote the first draft of the manuscript. GK reviewed drafts of the work, contributed to the conception and design of the work, and revised the analyses of the data and the work. WC analysed and interpreted the data, revised the work. IS reviewed drafts of the work, contributed to the conception and design of the work, and revised the work. All authors made 
substantial contributions to conception and design, acquisition of data, or analysis and interpretation of data; took part in drafting the article or revising it critically for important intellectual content; agreed to submit to the current journal; gave final approval of the version to be published; and agree to be accountable for all aspects of the work.

\section{Funding}

There is no funding to report.

\section{Disclosure}

The authors report no conflicts of interest for this work.

\section{References}

1. Kearney PM, Whelton M, Reynolds K, Muntner P, Whelton PK, He J. Global burden of hypertension: analysis of worldwide data. Lancet. 2005;365(9455):217-223.

2. Organization WH. Prevention and Control of Noncommunicable Diseases: Guidelines for Primary Health Care in Low Resource Settings. World Health Organization; 2012.

3. AIHW. High blood pressure. Australian Institute for Health and Welfare. 2019. Available from: https://www.aihw.gov.au/reports/riskfactors/high-blood-pressure/contents/high-blood-pressure. Accessed May 23, 2020.

4. Khatib R, Schwalm J-D, Yusuf S, et al. Patient and healthcare provider barriers to hypertension awareness, treatment and follow up: a systematic review and meta-analysis of qualitative and quantitative studies. PLoS One. 2014;9(1):e84238-e84238. doi:10.1371/ journal.pone. 0084238

5. Krousel-Wood M, Thomas S, Muntner P, Morisky D. Medication adherence: a key factor in achieving blood pressure control and good clinical outcomes in hypertensive patients. Curr Opin Cardiol. 2004;19(4):4. doi:10.1097/01.hco.0000126978.03828.9e

6. Carvalho AS, Santos P. Medication adherence in patients with arterial hypertension: the relationship with Healthcare Systems' Organizational factors. Patient Prefer Adherence. 2019;13:1761-1774.

7. Lemay J, Waheedi M, Al-Sharqawi S, Bayoud T. Medication adherence in chronic illness: do beliefs about medications play a role? Patient Prefer Adherence. 2018;Volume 12:1687-1698. doi:10.2147/ PPA.S169236

8. Khayyat SM, Khayyat SMS, Hyat Alhazmi RS, Mohamed MMA, Abdul Hadi M. Predictors of medication adherence and blood pressure control among Saudi hypertensive patients attending primary care clinics: a Cross-Sectional Study. PLoS One. 2017;12(1): $\mathrm{e} 0171255$.

9. Boratas S, Kilic HF. Evaluation of medication adherence in hypertensive patients and influential factors. Pak J Med Sci. 2018;34 (4):959-963.

10. Van Steenis M, Driesenaar J, Bensing J, et al. Relationship between medication beliefs, self-reported and refill adherence, and symptoms in patients with asthma using inhaled corticosteroids. Patient Prefer Adherence. 2014;8:83-91.

11. Gatti ME, Jacobson KL, Gazmararian JA, Schmotzer B, Kripalani S. Relationships between beliefs about medications and adherence. $\mathrm{Am}$ $J$ Health Syst Pharm. 2009;66(7):657-664.

12. Al-Ruthia Y, Hong S, Graff C, Kocak M, Solomon D, Nolly R. Examining the relationship between antihypertensive medication satisfaction and adherence in older patients. Res Social Adm Pharm. 2017;13(3):602-613. doi:10.1016/j.sapharm.2016.06.013
13. Tibaldi G, Clatworthy J, Torchio E, Argentero P, Munizza C, Horne R. The utility of the necessity-concerns framework in explaining treatment non-adherence in four chronic illness groups in Italy. Chronic Illn. 2009;5(2):129-133. doi:10.1177/ 1742395309102888

14. Phillips LA, Diefenbach MA, Kronish IM, Negron RM, Horowitz CR. The necessity-concerns framework: a multidimensional theory benefits from multidimensional analysis. Ann Behav Med. 2014;48(1):7-16. doi:10.1007/s12160-013-9579-2

15. Jimenez K, Vargas C, Garcia K, Guzman H, Angulo M, Billimek J. Evaluating the validity and reliability of the beliefs about medicines questionnaire in low-income, Spanish-speaking patients with diabetes in the United States. Diabetes Educ. 2017;43(1):114-124. doi: $10.1177 / 0145721716675740$

16. Horne R, Chapman SCE, Parham R, Freemantle N, Forbes A, Cooper V. Understanding patients' adherence-related beliefs about medicines prescribed for long-term conditions: a meta-analytic review of the necessity-concerns framework. PLoS One. 2013;8 (12):e80633.

17. Pesantes MA, Lazo-Porras M, Abu Dabrh AM, et al. Resilience in vulnerable populations with type 2 diabetes mellitus and hypertension: a systematic review and meta-analysis. Can J Cardiol. 2015;31 (9):1180-1188. doi:10.1016/j.cjca.2015.06.003

18. Fábos A. Refugees in the Arab Middle East: academic and policy perspectives. Domes. 2015;24(1):96-110. doi:10.1111/dome.12056

19. Shelton T. Refugee week: the number of globally displaced people reaches record high of 70.8 million. 2019. Available from: https:// www.abc.net.au/news/2019-06-22/world-refugee-week-who-iscoming-to-australia-and-why/11223982. Accessed October 12, 2020.

20. Parliament of Australia. Refugee resettlement to Australia: what are the facts? Parliament of Australia. 2016. Available from: https:// www.aph.gov.au/About_Parliament/Parliamentary_Departments/ Parliamentary_Library/pubs/rp/rp1617/RefugeeResettlement\#_ Toc461022121. Accessed July 8, 2019.

21. Shahin W, Stupans I, Kennedy G. Health beliefs and chronic illnesses of refugees: a systematic review. Ethn Health. 2018;1-13.

22. Mumford W. What is the difference between asylum seekers, refugees and economic migrants? 2016. Available from: https://www.sbs. com.au/news/dateline/explainer/what-difference-between-asylumseekers-refugees-and-economic-migrants. Accessed June 15, 2018.

23. Edwards A. UNHCR viewpoint: 'Refugee' or 'migrant' - which is right? 2016. Available from: UNHCR. http://www.unhcr.org/news/ latest/2016/7/55df0e556/unhcr-viewpoint-refugee-migrant-right.html. Accessed June 10, 2018.

24. Shahin W, Kennedy GA, Cockshaw W, Stupans I, Cabieses B. The role of refugee and migrant migration status on medication adherence: mediation through illness perceptions. PLoS One. 2020;15(1): e0227326. doi: $10.1371 /$ journal.pone. 0227326

25. Al Qasem A, Smith F, Cliffor S. Review: adherence to medication among chronic patients in Middle Eastern Countries: review of studies. East Mediterr Health J. 2011;17(04):357-358. doi:10.26719/2011.17.4.356

26. Al-Noumani H, Wu JR, Barksdale D, Sherwood G, AlKhasawneh E, Knafl G. Health beliefs and medication adherence in patients with hypertension: a systematic review of quantitative studies. Patient Educ Couns. 2019;102(6):1045-1056.

27. Al-Noumani H, Wu J-R, Barksdale D, Alkhasawneh E, Knafl G, Sherwood G. Relationship between medication adherence and health beliefs among patients with hypertension in Oman: Pilot study. Sultan Qaboos Univ Med J. 2017;17(3):e329. doi:10.18295/ squmj.2017.17.03.012

28. Australian Institute of Health and Welfare. Australia's Health 2016. Australian Institute of Health and Welfare; 2016. Available from: https://www.aihw.gov.au/getmedia/666de2ad-1c92-4db3-9c011368ba3c8c98/ah16-3-3-chronic-disease-comorbidities.pdf.aspx. Accessed October 3, 2019. 
29. Morisky DE, Green LW, Levine DM. Concurrent and predictive validity of a self-reported measure of medication adherence. Med Care. 1986;24(1):67-74. doi:10.1097/00005650-198601000-00007

30. Khan MU, Shah S, Hameed T. Barriers to and determinants of medication adherence among hypertensive patients attended National Health Service Hospital, Sunderland. J Pharm Bioallied Sci. 2014;6(2):104-108. doi:10.4103/0975-7406.129175

31. Mann M, Ponieman D, Leventhal H, Halm A. Predictors of adherence to diabetes medications: the role of disease and medication beliefs. J Behav Med. 2009;32(3):278-284. doi:10.1007/s10865009-9202-y

32. Brooks CM, Richards JM, Kohler CL, et al. Assessing adherence to asthma medication and inhaler regimens: a psychometric analysis of adult self-report scales. Med Care. 1994;32(3):298-307. doi:10.1097/ 00005650-199403000-00008

33. Erickson SR, Coombs JH, Kirking DM, Azimi AR. Compliance from self-reported versus pharmacy claims data with metered-dose inhalers. Ann Pharmacother. 2001;35(9):997-1003. doi:10.1345/ aph.10379

34. Horne R, Weinman J, Hankins M. The beliefs about medicines questionnaire: the development and evaluation of a new method for assessing the cognitive representation of medication. Psychol Health. 1999;14(1):1-24

35. The SAGE encyclopedia of communication research methods. 2017.

36. Hayes AF PROCESS: a versatile computational tool for observed variable mediation, moderation, and conditional process modeling [White paper]. 2012.

37. Sobel ME. Some new results on indirect effects and their standard errors in covariance structure models. Sociol Methodol. 1986;16:159-186. doi:10.2307/270922

38. Preacher KJ, Hayes AF. Asymptotic and resampling strategies for assessing and comparing indirect effects in multiple mediator models. Behav Res Methods. 2008;40(3):879-891. doi:10.3758/ BRM.40.3.879

39. Aikens JE, Nease DE Jr, Nau DP, Klinkman MS, Schwenk TL. Adherence to maintenance-phase antidepressant medication as a function of patient beliefs about medication. Ann Fam Med. 2005;3(1):23-30. doi:10.1370/afm.238

40. Horne R, Parham R, Driscoll R, Robinson A. Patients' attitudes to medicines and adherence to maintenance treatment in inflammatory bowel disease. Inflamm Bowel Dis. 2009;15(6):837-844. doi:10.1002/ibd.20846
41. Unni E, Shiyanbola OO. Clustering medication adherence behavior based on beliefs in medicines and illness perceptions in patients taking asthma maintenance medications. Curr Med Res Opin. 2016;32(1):113-121.

42. Bussell JK, Cha E, Grant YE, Schwartz DD, Young LA. Ways health care providers can promote better medication adherence. Clin Diabetes. 2017;35(3):171-177. doi:10.2337/cd016-0029

43. Shahin W, Kennedy GA, Stupans I. The impact of personal and cultural beliefs on medication adherence of patients with chronic illnesses: a systematic review. Patient Prefer Adherence. 2019;13:1019-1035. doi:10.2147/PPA.S212046

44. Amara AH, Aljunid SM. Noncommunicable diseases among urban refugees and asylum-seekers in developing countries: a neglected health care need. Global Health. 2014;10(1):24. doi:10.1186/17448603-10-24

45. Hjelm K, Nyberg P, Isacsson A, Apelqvist J. Beliefs about health and illness essential for self-care practice: a comparison of migrant Yugoslavian and Swedish diabetic females. J Adv Nurs. 1999;30 (5):1147-1159.

46. Njeru J, Formea C, Osman A, et al. Diabetes knowledge, attitudes and behaviors among Somali and Latino Immigrants. J Immigr Minor Health. 2016;18(6):1432-1440. doi:10.1007/s10903-015-0335-5

47. Hjelm K, Bard K, Nyberg P, Apelqvist J. Religious and cultural distance in beliefs about health and illness in women with diabetes mellitus of different origin living in Sweden. Int J Nurs Stud. 2003;40 (6):627-643.

48. Gil-González D, Carrasco-Portiño M, Vives-Cases C, AgudeloSuárez AA, Castejón Bolea R, Ronda-Pérez E. Is health a right for all? An umbrella review of the barriers to health care access faced by migrants. Ethn Health. 2015;20(5):1-19.

49. Roldan PC, Ho GY, Ho PM. Updates to adherence to hypertension medications. Curr Hypertens Rep. 2018;20(4):34.

50. MacFarlane A, Glynn LG, Mosinkie PI, Murphy AW. Responses to language barriers in consultations with refugees and asylum seekers: a telephone survey of Irish general practitioners. BMC Fam Pract. 2008;9(1):68. doi:10.1186/1471-2296-9-68

51. Li -W-W, Stewart AL, Stotts N, Froelicher ES. Cultural Factors Associated with antihypertensive medication adherence in Chinese immigrants. J Cardiovasc Nurs. 2006;21(5):354-362. doi:10.1097/ 00005082-200609000-00005
Patient Preference and Adherence

\section{Publish your work in this journal}

Patient Preference and Adherence is an international, peer-reviewed, open access journal that focusing on the growing importance of patient preference and adherence throughout the therapeutic continuum. Patient satisfaction, acceptability, quality of life, compliance, persistence and their role in developing new therapeutic modalities and compounds to optimize clinical outcomes for existing disease states are major areas of interest for the journal. This journal has been accepted for indexing on PubMed Central. The manuscript management system is completely online and includes a very quick and fair peer-review system, which is all easy to use. Visit http:// www.dovepress.com/testimonials.php to read real quotes from published authors. 